Erratum

Med Klin Intensivmed Notfmed

https://doi.org/10.1007/s00063-021-00817-0

(c) Der/die Autor(en) 2021

M. Lorsbach ${ }^{1}$ A. Gillessen ${ }^{2} \cdot$ K. Revering ${ }^{3} \cdot$ C. Juhra ${ }^{1}$

'Stabsstelle für Telemedizin, Universitätsklinikum Münster, Münster, Deutschland

${ }^{2}$ Klinik für Innere Medizin, Herz-Jesu-Krankenhaus Hiltrup GmbH, Münster-Hiltrup, Deutschland

${ }^{3}$ Zentrale Notaufnahme, Herz-Jesu-Krankenhaus Hiltrup GmbH, Münster-Hiltrup, Deutschland

\title{
Erratum zu: Informationen zur medizinischen Vorgeschichte in der Notaufnahme
}

\section{Erratum zu:}

Med Klin Intensivmed Notfmed 2020

https://doi.org/10.1007/s00063-020-

00661-8

Der Beitrag „Informationen zur medizinischen Vorgeschichte in der Notaufnahme"von M. Lorsbach, A. Gillessen, K. Revering und C. Juhra wurde ursprünglich am 10. Februar 2020 ohne „Open Access“ online auf der Internetplattform des Verlags publiziert. Die Autoren haben sich jedoch nachträglich für eine „Open-Access"-Veröffentlichung entschieden. Das Urheberrecht des Artikels wurde deshalb am 17. März 2021 in (C) The Author(s) 2020 geändert.

\section{Korrespondenzadresse}

\section{Lorsbach}

Stabsstelle für Telemedizin, Universitätsklinikum Münster

Hüfferstr. 73-79, 48149 Münster, Deutschland

m.lorsbach@uni-muenster.de

Funding. Open access funding enabled and organized by Projekt DEAL.

Open Access. Dieser Artikel wird unter der Creative Commons Namensnennung 4.0 International Lizenz veröffentlicht, welche die Nutzung, Vervielfältigung, Bearbeitung, Verbreitung und Wiedergabe in jeglichem Medium und Format erlaubt, sofern Sie den/die ursprünglichen Autor(en) und die Quelle ordnungsgemäß nennen, einen Link zur Creative Commons Lizenz beifügen und angeben, ob Änderungen vorgenommen wurden.

Die in diesem Artikel enthaltenen Bilder und sonstiges Drittmaterial unterliegen ebenfalls der genannten Creative Commons Lizenz, sofern sich aus der Abbildungslegende nichts anderes ergibt. Sofern das betreffende Material nicht unter der genannten Creative Commons Lizenz steht und die betreffende Handlung nicht nach gesetzlichen Vorschriften erlaubt ist, ist für die oben aufgeführten Weiterverwendungen des Materials die Einwilligung des jeweiligen Rechteinhabers einzuholen.

Weitere Details zur Lizenz entnehmen Sie bitte der Lizenzinformation auf http://creativecommons.org/ licenses/by/4.0/deed.de.
Die Online-Version des Originalartikels ist unter https://doi.org/10.1007/s00063-020-00661-8 zufinden. 